\title{
Determinan Tingkat Kepuasan Mahasiswa Vokasi Mengikuti Kuliah Daring di Masa Pandemi Covid-19
}

\author{
Supardi ${ }^{1}$ \\ Akademi Akuntansi YKPN Jogjakarta, \\ Indonesia
}

Surel : mas_sidiq@yahoo.com

\section{ABSTRAK}

Artikel ini membahas hubungan antara social presence, cognitive absorption, dan student satisfaction mahasiswa perguruan tinggi vokasi dalam pembelajaran online. Sebuah model persamaan struktural yang dihipotesiskan dikembangkan untuk mempelajari variabel - variabel penting yang dapat mempengaruhi interaksi dalam lingkungan pembelajaran daring. Data diperoleh melalui kuesioner dari 448 mahasiswa perguruan tinggi vokasi di Yogyakarta. Data dianalisis dengan Structural Equation Modeling - Partial Least Square (PLS) menggunakan Smart PLS 2.0. Hasil penelitian menunjukkan bahwa social presence dan cognitive absorption mahasiswa perguruan tinggi vokasi berdampak langsung pada student satisfaction.

Kata Kunci: $\begin{aligned} & \text { Social Presence; Cognitive Absorption; Student } \\ & \text { Satisfaction. }\end{aligned}$

\section{Determinants of Vocational Student Satisfaction Levels} Following Online Lectures during the Covid-19 Pandemic

\section{ABSTRACT}

This article investigates the relationships between social presence, cognitive absorption, and satisfaction of vocational college students in online learning. A hypothesized structural equation model was developed to study these critical variables that may influence interaction in online learning environments. Data was obtained through questionnaires from 448 students of vocational college at Yogyakarta. Data was analyzed by Structural Equation Modelling - Partial Least Square (PLS) using Smart PLS 2.0. The results of this research shows that the social presence and cognitive absorption of vocational college students is impact satisfaction directly.

Keywords: Social Presence; Cognitive Absorption; Student Satisfaction.

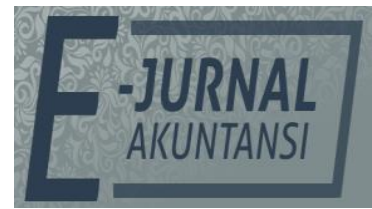

e-ISSN 2302-8556

Vol. 31 No. 3

Denpasar, Maret 2021

Hal. 677-692

DOI:

10.24843/EJA.2021.v31.i03.p12

PENGUTIPAN:

Supardi, \& Ashari, S. (2021).

Determinan Tingkat

Kepuasan Mahasiswa Vokasi Mengikuti Kuliah Daring di Masa Pandemi Covid-19. EJurnal Akuntansi, 31(3), 677-

RIWAYAT ARTIKEL:

Artikel Masuk:

21 Desember 2020

Artikel Diterima:

25 Maret 2021

Artikel dapat diakses : https://ojs.unud.ac.id/index.php/Akuntansi/index 


\section{PENDAHULUAN}

Pemanfaatan teknologi informasi di Indonesia terus bertumbuh. Hal ini tampak dari data di Kominfo tahun 2018 bahwa pengguna internet sebesar 143,26 juta atau sebesar $54,68 \%$ dari total populasi penduduk Indonesia. Akses internet oleh penduduk Indonesia rata-rata per hari selama 9 jam menggunakan berbagai perangkat digital atau saat menggunakan ponsel/smartphone dilakukan selama 4 jam. Waktu akses internet penduduk Indonesia lebih lama dibandingkan dengan waktu akses internet penduduk Amerika Serikat yang hanya 6,5 jam menggunakan perangkat digital atau 2 jam menggunakan ponsel/smartphone. Berdasarkan fakta ini, seharusnya penggunaan internet di Indonesia dapat dimanfaatkan secara optimal khususnya untuk tujuan peningkatan mutu dan relevansi pendidikan tinggi.

Dalam menghadapi era disrupsi teknologi dan masa pandemi Covid-19 saat ini serta mengacu pada Permenristekdikti 51/2018, salah satu upaya dalam pemanfaatan internet dan teknologi informasi adalah menyelenggarakan proses belajar mengajar jarak jauh. Pembelajaran jarak jauh tumbuh secara subtansial dan terus berkembang sejalan dengan kuatnya pengaruh pemanfaatan teknologi informasi dan komunikasi (Leong, 2011). Pada masa pandemi Covid-19 saat ini, pelaksanaan pembelajaran yang dilakukan oleh perguruan tinggi bergeser dari tatap muka ke pembelajaran jarak jauh. Pelaksanaannya dilakukan oleh perguruan tinggi secara terpadu pada semua aktivitas presentasi, interaksi dan evaluasi melalui penggunaan teknologi berbasis internet. Oleh sebab itu, pelaksanaan pembelajaran jarak jarak jauh secara online (daring) perlu memahami batasan bahwa kuliah daring merupakan pembelajaran terencana yang berlangsung secara terpisah dengan pendidiknya, memerlukan desain dan teknik pembelajaran yang khusus, berkomunikasi melalui berbagai teknologi, serta menggunakan struktur organisasi dan administrasi yang khusus.

Mengacu pada penjelasan di atas, pelaksanaan kuliah daring tidak serta merta dapat berjalan lancar, banyak faktor yang dapat menimbulkan permasalahan baik bagi pengajar maupun mahasiswa. Untuk itu perlu diupayakan secara optimal pengadaan bahan ajar, teknologi, sarana prasarana dan pengelolaan agar pelaksanaan kuliah daring dapat diterima semua pihak. Leong (2011) menyatakan bahwa selain pengadaan material bahan ajar dan teknologi dalam mendukung kuliah daring, perlu juga diupayakan untuk dapat memahami para pihak yang terlibat sehingga tetap tercipta suatu kepuasan dalam mengikuti kuliah daring dan kualitas pembelajaran tetap terjaga.

Untuk dapat memahami kepuasan pihak-pihak yang terlibat dalam kuliah daring merupakan hal yang sulit, akan tetapi beberapa penelitian telah menemukan faktor-faktor yang mempengaruhi tingkat kepuasanan khususnya bagi mahasiswa (Leong, 2011). Penelitian-penelitian sebelumnya yang meneliti tentang tingkat kepuasan mahasiswa dan faktor-faktor yang mempengaruhi dalam mengikuti kuliah daring antara lain dilakukan oleh Leong et al. (2002). Bolliger \& Martindale (2004) dan Leong (2011). Penelitian Bolliger \& Martindale (2004) telah menemukan bahwa faktor yang berasal dari pengajar seperti komunikasi, umpan balik, persiapan, pengetahuan, metode mengajar, dorongan, profesionalisme dan interaktivitas merupakan faktor penting yang mempengaruhi kepuasan mahasiswa. Sementara penelitian Leong et al. (2002) 
menemukan faktor yang dapat mempengaruhi tingkat kepuasan mahasiswa dalam mengikuti kuliah daring seperti interaksi, aspek pengajar, teknologi, tingkat kesulitan, dan fungsi khusus dari teknologi yang digunakan.

Selain faktor-faktor yang telah ditemukan dalam penelitian-penelitian sebelumnya, ada satu faktor yang dianggap penting terkait dengan kepuasan mahasiswa, yaitu social presence (Richardson \& Swan, 2003), (Hostetter \& Busch, 2006) (Cobb, 2009), (Leong, 2011), (Sorden \& Ramírez-Romero, 2012), dan (Richardson et al., 2017). Richardson et al. (2017) melakukan meta-analysis terhadap hasil penelitian-penelitian sebelumnya terkait hubungan antara social presence dan student satisfaction. Hasil penelitian menunjukkan bahwa sebagian besar dari penelitian sebelumnya menunjukkan hubungan yang signifikan dan dibuktikan kembali oleh Richardson et al. (2017) yang menguji kembali hubungan antara social presence dan student satisfaction dengan menggunakan Pearson's Correlation Metric. Meski social presence mempunyai pengaruh kuat terhadap kepuasan mahasiswa dalam lingkungan pembelajaran online, tetapi ditemukan adanya kesenjangan dari penelitian sebelumnya terutama jika dikaitkan dengan desain fasilitas, dan outcomes dalam menciptkan lingkungan pembelajaran online yang efektif (Richardson et al., 2017). Untuk itu, perlu dilakukan pengujian kembali dengan melibatkan variabel lain, seperti cognitive absorption dan interest (Leong, 2011).

Penelitian ini merupakan replikasi dari model penelitian yang dilakukan oleh Leong (2011) yang meneliti peran social presence dan cognitive absorption dalam membentuk tingkat kepuasan mahasiswa yang ikut serta di lingkungan pembelajaran virtual/online. Hal ini sejalan saran dari Leong (2011) agar dilakukan pengujian secara bersama hubungan antara variabel social presence dan cognitive absorption dengan tingkat kepuasan mahasiswa. Berdasarkan hal tersebut dan sepanjang pengetahuan peneliti, penelitian yang meneliti tentang hubungan social presence dan cognitive absorption dengan kepuasan mahasiswa khususnya mahasiswa perguruan tinggi vokasi dalam mengikuti kuliah daring belum banyak diteliti. Yang membedakan penelitian ini dengan penelitian Leong (2011) adalah penggunaan mahasiswa perguruan tinggi vokasi sebagai responden dan penelitian ini menggunakan social cognitive theory untuk menjelaskan hubungan antar konstruk. Selain itu, untuk menganalisi data serta pengambilan kesimpulan, penelitian ini menggunakan Structural Equation Modelling (SEM).

Berdasarkan penjelasan tersebut, pertanyaan penelitian yang dikembangkan adalah apakah mahasiswa perguruan tinggi vokasi merasa puas mengikuti kuliah daring? Faktor-faktor apa saja yang menjadi penentu kepuasan mahasiswa perguruan tinggi vokasi untuk mengikuti kuliah daring? Sehingga, tujuan penelitian ini adalah untuk mengetahui faktor-faktor apa sajakah yang dapat menentukan kepuasan mahasiswa perguruan tinggi vokasi mengikuti kuliah daring dan untuk mengetahui apakah konstruk social presence dan cognitive absorption memengaruhi kepuasan mahasiswa perguruan tinggi vokasi untuk mengikuti kuliah daring.

Social cognitive theory merupakan model yang robust serta mulai banyak diterima dan secara empiris sudah banyak divalidasi untuk penelitian mengenai perilaku individu mengenai hubungan timbal balik antara kognitif individual, 
lingkungan dan pengaruh perilaku. Bandura (1977) menyatakan bahwa social cognitive theory merupakan teori yang berbasis pada premis bahwa pengaruhpengaruh lingkungan semacam tekanan-tekanan sosial atau karakteristikkarakteristik situasional unik, kognitif dan faktor-faktor personal lainnya termasuk personaliti dan juga karakteristik-karakteristik demografik, dan perilaku saling mempengaruhi satu dengan yang lainnya. Lingkungan atau karakteristik-karakteristik situasional mempengaruhi perilaku pada situasi tertentu yang kemudian gilirannya dipengaruhi kembali oleh perilaku. Akhirnya, perilaku dipengaruhi oleh kognitif atau faktor-faktor personal dan gilirannya perilaku mempengaruhi faktor-faktor personal tersebut. Hubungan timbal balik antara lingkungan (karakteristik-karakteristik situasional), perilaku dan kognitif (faktor-faktor personal) disebut oleh Bandura (1986) sebagai hubungan timbal-balik segitiga (triadic reciprocality).s

Social cognitive theory telah banyak digunakan sebagai dasar teori dalam penelitian-penelitian bidang sistem teknologi, seperti penelitian yang dilakukan oleh Agarwal \& Karahanna (2000), Chandra et al. (2012), Supardi (2014) dan Supardi \& Asamara (2015). Mereka melakukan penelitian dengan menggunakan cognitive absorption sebagai konstruk dalam menggambarkan hubungan timbal balik segitiga yang sesuai dengan social cognitive theory. Penelitian Agarwal \& Karahanna (2000) menunjukkan bahwa cognitive absorption sebagai konstruk yang digunakan untuk menjelaskan pengalaman kognitif individu dalam menggunakan teknologi. Hasil penelitian tersebut menunjukkan bahwa cognitive absorption secara signifikan berpengaruh terhadap perceived ease of use dan perceived usefulness. Berdasarkan bentuk hubungan timbal-balik segitiga yang ada pada social cognitive theory, Agarwal \& Karahanna (2000) menemukan bahwa karakteristik individual yaitu computer playfulness dan personal innovativeness merupakan faktor penentu yang penting bagi cognitive absorption. Sedangkan penelitian Supardi (2014) dan Supardi \& Asamara (2015) melakukan pengujian hubungan norma sosial dengan cognitive absorption diperoleh bahwa norma sosial berpengaruh secara positif.

Penggunaan konstruk cognitive absorption dalam penelitian-penelitian bidang sistem teknologi informasi, mulai diperkenalkan oleh Agarwal et al. (1997) dan dikembangkan oleh Agarwal \& Karahanna (2000). Dalam penelitian Agarwal \& Karahanna (2000), dasar teoritis cognitive absorption yang digunakan berasal dari tiga aliran penelitian, yaitu personality trait of absorption, the state of flow dan the notion of cognitive engagement. Menurut aliran the state of flow (Mirvis \& Csikszentmihalyi, 1991), cognitive absorption merupakan keadaan dari manusia yang terlibat dalam suatu aktivitas dan tidak ada satupun tampak menjadi masalah. Mirvis \& Csikszentmihalyi (1991) juga mengatakan bahwa flow merupakan keadaan dari pengalaman optimal yang dapat terjadi tidak hanya dalam pencarian aktivitas fisik, tetapi juga dalam interaksi dengan sistem. Berdasarkan aliran yang membentuk cognitive absorption, Agarwal \& Karahanna (2000) menjelaskan konsep cognitive absorption menggunakan lima dimensi yaitu temporal dissociation atau ketidakmampuan untuk mempertimbangkan waktu selama terlibat dalam interaksi, focused immertion atau pengalaman dari total engagement yang perhatian lainnya diperlukan, yang pokok atau utama, diabaikan, heightened enjoyment atau memperoleh aspek kesenangan dalam 
berinteraksi, control atau mewakilkan persepsi pengendalian pengguna terhadap keterlibatannya dari berinteraksi dan curiosity atau keinginan memperluas pengalaman yang menimbulkan sensitivitas dan rasa penasaran.

Pada penelitian Agarwal \& Karahanna (2000), mereka mendefinisikan cognitive absorption sebagai keadaan dari keterlibatan secara mendalam seseorang dengan software. Seiring dengan berkembangnya penelitian sistem teknologi yang menggunakan konstruk cognitive absorption, Chandra et al. (2012) dalam penelitian mengenai penggunaan teknologi virtual worlds mendefinisi cognitive absorption sebagai keadaan dari keterlibatan yang dalam atau pengalaman menyeluruh (holistic experience) individu saat menggunakan teknologi informasi. Dari definisi tersebut, Agarwal \& Karahanna (2000) dan Chandra et al. (2012) beragumen bahwa cognitive absorption diyakini sebagai anteseden yang membentuk kepercayaan-kepercayaan individu dalam menggunakan teknologi.

Penelitian mengenai social presence semakin banyak bermunculan semenjak Garrison et al. (1999) mengemukakan kerangka kelompok bertanya atau community of inquiry (Tantri, 2018). Menurut Garrison et al. (1999), social presence merupakan kemampuan partisipan dalam Community of Inquiry (CoI) untuk memproyeksikan diri mereka secara sosial dan emosional sebagai individu yang nyata. Kerangka CoI terinspirasi dari kegiatan belajar mengajar di kelas konvensional yang menitikberatkan pada pentingnya kehadiran pengajar dan pembelajar sebagai kunci partisipan dalam kesuksesan kegiatan pembelajaran (Garrison et al., 1999). Karena kelas konvensional telah terbukti mampu meningkatkan proses pengajaran dan menambah pembelajaran di dalam kelas serta dengan kehadiran pengajar dan pembelajar dapat mengembangkan kemampuan berkelompok (Tantri, 2018). Kerangka Community of Inquiry menempatkan 3 (tiga) elemen dalam pembelajaran daring, yaitu elemen kognitif, elemen pengajaran, dan elemen social presence. Kerangka CoI merupakan salah satu model pembelajaran yang melihat bahwa pembelajaran akan sukses dalam suatu kelompok karena adanya interaksi tiga elemen tersebut (Garrison et al., 1999). Elemen social presence sebagai salah satu kerangka CoI disebabkan kesuksesan pembelajaran dengan menggunakan komunikasi yang dimediasi komputer dan diharapkan mampu membawa iklim social presence seperti kelas konvensional (Kosasih \& Iqbal, 2013).

Penelitian mengenai social presence telah banyak dilakukan dan bentuknya terus berkembang karena para peneliti mulai dapat mengukur tingkatan social presence dalam pembelajaran daring (Tantri, 2018). Pada mulanya, penelitian social presence dlakukan dengan konten analisa yang dilakukan dengan mengodekan jumlah emotikon yang dipakai di dalam posting pembelajar dan diidentifikasi bentuk kehadirannya. Namum hal ini tidak bisa digunakan terus menerus, dikarenakan metode penelitian analisa konten tidak bisa mengidentifikasi bentuk social presence yang melibatkan interaksi berpikir kritis (Garrison et al., 2010). Oleh sebab itu, Rovai (2002) mengembangkan instrumen untuk mengukur kehadiran komunitas kelas dalam suatu kelas jarak jauh dengan menggunakan internet. Kehadiran komunitas kelas diteliti dikarenakan banyaknya jumlah rata-rata pembelajar yang keluar (drop-out) selama pembelajaran daring berlangsung karena merasa berkurangnya rasa kebersamaan dengan adanya rasa ketidaksambungan, terisolasi, terdistraksi, dan 
kekurangan perhatian individu yang dapat mempengaruhi pembelajar dalam melakukan pembelajan daring jarak jauh.

Penelitian yang dilakukan Akcaoglu \& Lee (2016) melalui small discussion group dengan menekankan pada segi kemampuan sosial, lingkungan soial dan kerjasama grup pembelajar. Hasil penelitian menunjukkan semakin sedikit anggota grup maka akan meningkatkan social presence. Penelitian Swan \& Shih (2019) menemukan hubungan antara kesadaran social presence dan satisfaction dalam berdiskusi daring. Kesadaran kehadiran tutor lebih mempengaruhi kepuasan pembelajar daripada kesadaran kehadiran akan teman sebaya. Hasil penelitian Swan \& Shih (2019) menunjukkan bahwa pembelajar akan cenderung mempunyai kesadaran social presence yang tinggi dan akan berkontribusi dalam forum diskusi saat pembelajaran daring.

Penggunaan konstruk social presence terus berkembang dalam penelitianpenelitian terkait dengan kuliah yang menggunakan komputer sebagai media komunikasi seperti yang sekarang ini banyak dilakukan oleh perguruan tinggi tidak terkecuali pada perguruan tinggi vokasi yang lebih banyak menekankan pada praktek. Hal ini menunjukkan bahwa konstruk social presence dianggap sebagai karakteristik media komunikasi (Leong, 2011) dan salah satu komponen krusial dari kualitas pembelajaran secara daring yang dirasakan oleh mahasiswa (Cobb, 2009) dan (Horzum, 2015). Oleh sebab itu, social presence sangat tergantung pada kualitas tujuan dari pembelajaran (Leong, 2011) dan dipengaruhi oleh karakteristik pengguna (Horzum, 2015). Sebagai contoh, pembelajaran secara daring yang lebih interaktif dan kehadiran sosial para peserta yang cukup tinggi, akan membuat pengguna khususnya mahasiswa akan lebih puas dan merasa memperoleh manfaat yang sama dengan kuliah secara luring (konvensional).

Walaupun penelitian-penelitian sebelumnya sepakat bahwa social presence merupakan anteseden dalam membentuk terjadinya perasaan satisfaction pada pembelajaran secara daring, akan tetapi hasil yang berbeda diperoleh dari penelitian-penelitian sebelumnya. Penelitian Leong (2011) diperoleh hasil yang tidak signifikan hubungan antara social presence dengan student satisfaction. Sedangkan penelitian yang menunjukkan bahwa social presence memiliki efek positif dalam membentuk kepuasan dan pencapaian mahasiswa dalam pembelajaran secara daring ditemukan dalam penelitian Richardson \& Swan (2003), Hostetter \& Busch (2006), Horzum (2015) dan Swan \& Shih (2019). Berdasarkan penjelasan di atas dan hasil penelitian sebelumnya yang lebih banyak diperoleh hubungan positif, maka hipotesis yang dikembangkan dalam penelitian ini sebagai berikut.

$\mathrm{H}_{1}$ : Social presence berhubungan secara positif dengan student satisfaction pada saat mahasiswaMperguruan tinggi vokasi mengikuti kuliah secara daring.

Mayoritas dari hasil penelitian sebelumnya dan dihipotesiskan dalam penelitian ini, sepakat bahwa social presence merupakan anteseden bagi satisfaction dan dianggap sebagai komponen penting dalam kesuksesan pembelajaran secara daring. akan tetapi penelitian sebelumnya belum banyak 
meneliti hubungan cognitive absorption dengan satisfaction secara langsung (Leong, 2011). Hal ini terbukti dengan tidak banyaknya literatur yang ditemukan peneliti terkait hubungan cognitive absorption dengan satisfaction secara langsung. Peneliti hanya menemukan penelitian sebelumnya yang menguji hubungan flow dengan satisfaction seperti penelitian Parameswaran \& Kishore (2017). Mereka menggunakan konstruk flow yang merupakan salah satu konstruk yang membentuk konstruk cognitive absorption dari penelitian Agarwal \& Karahanna (2000). Menurut Csikszentmihalyi (2014), flow merupakan sensasi menyeluruh yang dirasakan oleh seseorang ketika tindakannya menggunakan teknologi dilakukan secara mendalam. Sedangkan Agarwal \& Karahanna (2000) dan Chandra et al. (2012) Chandra et al. (2012) menyatakan bahwa cognitive absorption merupakan keadaan dari seseorang yang terlibat dalam suatu aktivitas secara mendalam dan menyeluruh terutama terkait dengan penggunaan sistem informasi.Sehingga konstruk flow dan konstruk cognitive absorption memiliki kesamaan makna.

Walaupun hubungan secara langsung antara cognitive absorption dengan satisfaction belum banyak dilakukan, tetapi berdasarkan penelitian yang dilakuan oleh Parameswaran \& Kishore (2017) diperoleh bahwa flow berhubungan positif signifikan dengan satisfaction. Sedangkan penelitian yang dilakukan oleh Leong (2011) terutama terkait dengan hubungan secara langsung cognitive absorption dengan satisfaction diperoleh hasil bahwa cognitive absorption memiliki hubungan positif terhadap kepuasan seseorang dalam lingkungan pembelajaran daring (online learning environment). Selain dari hasil penelitian sebelumnya, peneliti menduga bahwa saat sesorang mengalami keadaan cognitive absorption dalam menggunakan teknologi, akan meningkatkan kepuasan individu termasuk dalam rangka mengikuti kuliah secara daring. Berdasarkan hasil penelitian sebelumnya, maka hipotesis yang dikembangkan dalam penelitian ini sebagai berikut.

$\mathrm{H}_{2}$ : Cognitive absorption berhubungan secara positif dengan student satisfaction pada saat mahasiswa perguruan tinggi vokasi mengikuti kuliah secara daring.

Model penelitian ini melibatkan dua variabel independen yaitu social presence dan cognitive absorption serta satu variabel dependen yaitu student satisfaction dalam mengikuti kuliah daring. Gambar 1, berikut menyajikan hubungan antar konstruk penelitian.

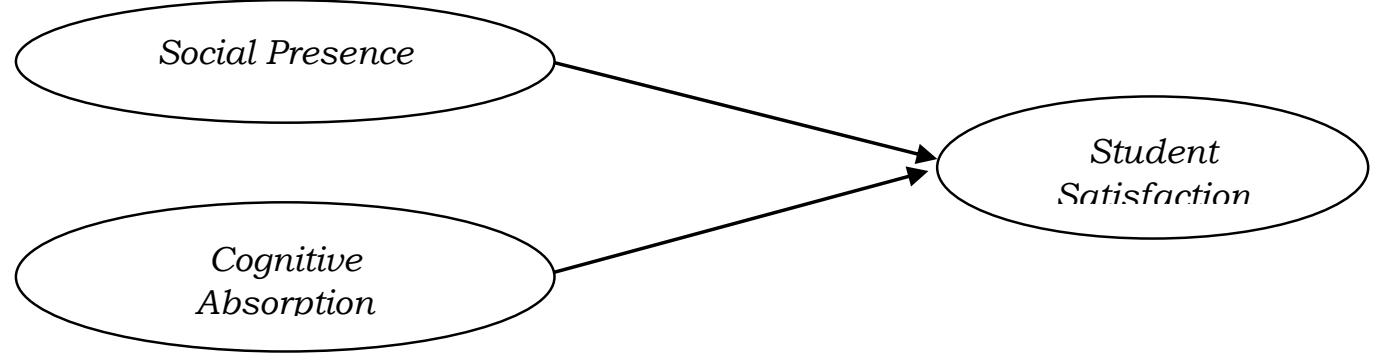

Gambar 1. Model Penelitian 
Sumber: Data Penelitian, 2019

\section{METODE PENELITIAN}

Populasi dalam penelitian ini adalah seluruh mahasiswa dan yang menjadi sampel dalam penelitian ini adalah mahasiswa perguruan tinggi vokasi. Untuk mewakili sampel, dipilih responden penelitian dengan pendekatan purposive sampling on respondent. Kriteria yang digunakan adalah responden harus merupakan mahasiswa perguruan tinggi vokasi yang pernah mengikuti kuliah secara daring. Kriteria ini dibuat agar responden sebagai perwakilan sampel yang digunakan dalam penelitian sesuai dengan tujuan penelitian yaitu untuk mengetahui kepuasan mahasiswa perguruan tinggi vokasi dalam mengikuti kuliah secara daring. Jumlah responden yang digunakan dalam penelitian ini menggunakan ukuran minimum sesuai dalam analisis SEM-PLS yaitu 10 kali jumlah indikator formatif terbesar pada suatu konstruk atau 10 kali dari jumlah jalur struktural terbesar yang mengarah pada suatu konstruk tertentu (Hair, 2015, dalam Sholihin \& Ratmono, 2013:12).

Kuisioner penelitian dibangun dengan mengacu pada pernyataanpernyataan dari model penelitian Leong (2011). Peneliti menggunakan 41 aitem pernyataan dengan rincian 16 aitem pernyataan yang mengukur social presence berasal dari penelitian Tu (2002), 20 aitem pernyataan yang mengukur cognitive absorption berasal dari penelitian Agarwal \& Karahanna (2000) dan 5 aitem pernyataan yang mengukur student satisfaction berasal dari Tallman (1994).

Pengukuran instrumen kuesioner dilakukan dengan menggunakan skala ordinal (likert), yaitu skala ukur yang memiliki kategori dan juga memiliki urutan. Kategori disini adalah kategori pilihan jawaban yang disediakan oleh peneliti. Setiap instrumen menggunakan skala likert 5 (sangat tidak setuju - tidak setuju - agak setuju - setuju - sangat setuju) yang memuat pernyataan-pernyataan yang mengukur social presence, cognitive absorption dan student satisfaction. Pada bagian pertama kuesioner memuat data demografi responden ditinjau dari gender, pengalaman mengikuti kelas daring dan lama penggunaan internet dalam satu hari.

Teknik pengumpulan data yang digunakan dalam penelitian ini adalah teknik survei. Survei yang dilakukan adalah survei yang dikirimkan lewat komputer (computer-delivered survey) dengan menyebarkan kuesioner secara online menggunakan media internet atau aplikasi whatsapp kepada individual yang mempunyai pengalaman atau pernah mengikuti kuliah daring. Untuk menjaga agar tingkat pengmbalian kuesioner tetap tinggi, peneliti menggunakan mahasiswa dari kelas yang diampu oleh masing-masing peneliti sebagai responden.

Analisis data dalam penelitian ini menggunakan pendekatan Structural Equation Modelling - Partial Least Square (SEM-PLS). Secara umum SEM-PLS sangat sesuai untuk memprediksi aplikasi dan membangun teori serta dapat melakukan pengujian model pengukuran sekaligus pengujian model struktural secara simultan (Hartono \& Abdillah, 2009:14). Pengolahan data menggunakan perangkat lunak Smart PLS 2.0 yang digunakan dalam pengujian model, pengujian struktural dan pengujian hipotesis (Hartono \& Abdillah, 2009:62). 
Pengujian model pengukuran dilakukan untuk menentukan validitas konstruk dan reliabilitas instrumen penelitian. Validitas konstruk terdiri dari validitas konvergen dan validitas diskriminan. Validitas konvergen diukur melalui nilai loading faktor $>0,7$, average variance extracted ( $A V E)>0,5$ dan communality $>0,5$. Pengujian validitas konvergen dilakukan melalui nilai AVE dan membandingkan antara akar AVE dengan korelasi konstruk variabel laten. Nilai AVE harus > 0,5 sedangkan akar AVE harus lebih tinggi daripada nilai korelasi konstruk lainnya (Hartono \& Abdillah, 2009:81). Validitas diskriminan diukur melalui cross loading yaitu masing-masing indikator suatu konstruk memiliki nilai loading faktor lebih tinggi dibandingkan dengan nilai pada konstruk lainnnya. Kriteria loading factor secara praktikal memenuhi nilai $>0,50$ (Hartono \& Abdillah, 2009:60). Pengujian reliabilitas dapat menggunakan dua metode yaitu Cronbach's alpha dan Composite Realibility. Rule of thumb nilai alpha atau Composite Reliability harus lebih besar dari 0,7 meskipun nilai 0,6 masih dapat diterima (Hair, Jr, 2015).

Pengujian model struktural dilakukan untuk menilai seberapa baik model yang diajukan untuk memprediksi konstruk yang diukur. Hal ini dievaluasi dengan melihat nilai $\mathrm{R}^{2}$ untuk konstruk dependen dan nilai koefisien path atau $t$ values tiap path untuk uji signifikansi antar konstruk (Hartono \& Abdillah, 2009:62). Pengujian hipotesis untuk memprediksi adanya hubungan kausalitas diperoleh melalui uji t-statistics yang dihasilkan dari proses bootstrap. Pengujian dilakukan dengan membandingkan nilai t-table dengan nilai t-statistics yang dihasilkan dari proses bootstrap. Tingkat signifikansi pengujian hipotesis ditunjukkan dengan nilai koefiesien path atau inner model yang ditunjukkan oleh nilai $\mathrm{t}$-statistik. Hipotesis diterima pada alpha 5\% jika nilai t-statistik diatas 1,64 untuk hipotesis satu ekor (one-tailed) dan di atas 2,33 untuk hipotesis satu ekor pada alpha 1\% (Hartono \& Abdillah, 2009:63).

\section{HASIL DAN PEMBAHASAN}

Kriteria responden yang telah ditentukan dalam penelitian ini yaitu mahasiswa perguruan tinggi vokasi dan telah mengikuti kuliah secara daring. Teknik pengumpulan data yang digunakan dalam penelitian ini adalah menggunakan metode penyebaran melalui internet (google form). Metode ini dipilih agar tingkat pengembalian kuesioner tinggi dan responden langsung mengisi menggunakan handphone yang dimiliki. Responden yang mengisi dan mengembalikan kuesioner sebanyak 448 responden dan seluruhnya dapat digunakan. Hal ini disebabkan karena responden mengisi secara lengkap atau tidak ada responden memberi tanggapan yang ekstrim atau tidak rasional.

Berdasarkan hasil distribusi frekuensi yang tersaji pada Tabel 1, responden penelitian ini didominasi oleh wanita yang memiliki proporsi sebanyak $81 \%$ atau 363 orang dibandingkan responden laki-laki yang hanya 29\%. Mayoritas dari responden ( $90 \%$ dari jumlah responden) dalam sehari menghabiskan waktu sekitar 4 jam saat menggunakan teknologi internet. Akan tetapi kebanyakan tidak digunakan untuk tujuan kuliah secara daring. Karena dari jumlah responden, sebanyak $86,4 \%$ responden belum pernah mengikuti kuliah secara daring atau selama ini lebih banyak mengikuti kuliah secara konvensional (hadir dan tatap muka di kelas). 
Tabel 1. Demografi Responden

\begin{tabular}{llcc}
\hline & & Jumlah & Prosentase \\
\hline Gender & Laki-laki & 85 & $29 \%$ \\
& Perempuan & 363 & $81 \%$ \\
Sebelum pandemi COVID-19, pernah & Pernah & 448 & $100 \%$ \\
menggunakan aplikasi atau & Belum Pernah & 309 & $68,9 \%$ \\
teknologi untuk menunjang kuliah & & 139 & $31,1 \%$ \\
secara online & & 448 & $100 \%$ \\
Sebelum pandemi COVID-19, pernah & Pernah & 61 & $13,6 \%$ \\
mengikuti kuliah secara online & Belum Pernah & 387 & $86,4 \%$ \\
& & 448 & $100 \%$ \\
Penggunaan teknologi internet & Kurang dari 1 jam & 10 & $2,2 \%$ \\
dalam sehari & $1-3$ jam & 27 & $6,0 \%$ \\
& $4-6$ jam & 115 & $25,7 \%$ \\
& $7-9$ jam & 126 & $28,1 \%$ \\
& Di atas 10 jam & 170 & $38,0 \%$ \\
& & 448 & $100 \%$ \\
\hline
\end{tabular}

Sumber: Data Penelitian, 2019

Pengujian model yang dilakukan dengan menggunakan SmartPLS 2.0 dan tampak pada Gambar 2, menunjukkan bahwa tidak semua indikator yang mengukur masing-masing konstruk memperoleh skor loading di atas 0,5. Akibatnya beberapa indikator untuk mengukur cognitive absorption dan social presence dihapus. Sehingga hanya indikator-indikator yang mempunyai skor loading di atas 0,5 saja yang digunakan untuk mengukur masing-masing konstruk dan digunakan dalam penelitian ini. Nilai tersebut telah sesuai rule of thumb yang biasanya digunakan untuk membuat pemeriksaan awal dari matrik faktor yang menurut Hair (2015) adalah untuk loading $\geq 0,50$ memiliki signifikan secara praktikal.

Penelitian ini menggunakan konstruk dengan indikator reflektif, sehingga uji validitas konvergen dari model pengukuran dalam penelitian ini dinilai berdasarkan loading factor indikator-indikator yang mengukur konstruk tersebut. Pengujian validitas konvergen menggunakan skor faktor loading dan dapat juga dilihat dari skor AVE dan Communality, yang masing-masing harus bernilai di atas 0,5. Semakin tinggi nilai AVE dan Communality, maka semakin baik validitas konvergen masing-masing konstruk.

Hasil pengujian validitas konvergen pada penelitian ini menunjukkan tingkat keakurasian yang tinggi seperti yang tersaji pada Tabel 2, dan Tabel 3. Seluruh indikator reflektif berdasarkan loading factor indikator-indikator yang mengukur konstruk penelitian memiliki muatan faktor loading > 0,50, AVE > 0,50, dan communality $>0,50$. Maka dapat disimpulkan untuk indikator pada penelitian ini memiliki nilai loading factor dan nilai AVE serta Communality yang signifikan dan memenuhi validitas konvergen. 
Tabel 2. Overview Smart PLS

\begin{tabular}{lccccc}
\hline & AVE & $\begin{array}{c}\text { Composite } \\
\text { Reliability }\end{array}$ & $\begin{array}{c}\text { Cronbachs } \\
\text { Alpha }\end{array}$ & R Square & Communality \\
\hline Cognitive Absorption & 0,553 & 0,941 & 0,931 & & 0,553 \\
Social Presence & 0,516 & 0,917 & 0,902 & & 0,516 \\
Student Satisfaction & 0,709 & 0,924 & 0,897 & 0,824 & 0,709 \\
\hline
\end{tabular}

Sumber: Data Penelitian, 2019

Validitas diskriminan dievaluasi berdasar skor cross loading. Indikatorindikator pada sebuah konstruk harus berkorelasi lebih tinggi pada konstruknya dibandingkan pada konstruk lain. Pada Tabel 3, tersaji bahwa semua indikator memiliki nilai lebih tinggi pada konstruknya daripada konstruk lainnya.

Tabel 3. Cross Loading

\begin{tabular}{lccc}
\hline & Cognitive Absorption & Social Presence & Student Satisfaction \\
\hline CA1 & 0,880450 & 0,780757 & 0,703923 \\
CA2 & 0,671307 & 0,592285 & 0,538690 \\
CA3 & 0,656214 & 0,578155 & 0,553617 \\
CA4 & 0,874431 & 0,772345 & 0,869482 \\
CA5 & 0,602177 & 0,504411 & 0,456072 \\
CA6 & 0,833206 & 0,745832 & 0,658003 \\
CA7 & 0,812109 & 0,697803 & 0,651970 \\
CA8 & 0,880450 & 0,780757 & 0,703923 \\
CA9 & 0,681556 & 0,573088 & 0,529448 \\
CA10 & 0,647404 & 0,586906 & 0,544384 \\
CA11 & 0,755369 & 0,678190 & 0,642243 \\
CA12 & 0,575884 & 0,570491 \\
CA13 & 0,681733 & 0,616310 & 0,602349 \\
SP1 & 0,720935 & 0,640924 & 0,520089 \\
SP2 & 0,481080 & 0,870895 & 0,854452 \\
SP3 & 0,763554 & 0,866414 & 0,841699 \\
SP4 & 0,739708 & 0,666590 & 0,505323 \\
SP5 & 0,545158 & 0,694971 & 0,545017 \\
SP6 & 0,572930 & 0,880757 & 0,703923 \\
SP7 & 0,668046 & 0,532240 \\
SP8 & 0,780450 & 0,771789 & 0,616946 \\
SP9 & 0,570517 & 0,627337 & 0,394871 \\
SP10 & 0,883562 & 0,469243 \\
SP11 & 0,827651 & 0,805866 \\
SS1 & 0,814177 & 0,843153 \\
SS2 & 0,696925 & 0,855464 \\
SS3 & 0,772345 & 0,831014 \\
SS4 & 0,673289 & 0,869482 \\
SS5 & 0,394759 & & 0,810294 \\
\hline Sut & 0,68421 &
\end{tabular}

Sumber: Data Penelitian, 2019 
Hal ini mengindikasikan bahwa semua indikator berkorelasi lebih tinggi dengan masing-masing konstruk daripada berkorelasi dengan konstruk lainnya. Sebagai contoh semua indikator dari konstruk cognitive absorption lebih tinggi skor cross loading dibandingkan dengan indikator-indikator pada konstruk social presence dan student satisfaction.

Reliabilitas dilakukan dengan melihat nilai composite reliability. Pada Tabel 2 , tersaji bahwa nilai composite reliability $>0,70$. Dari pengujian composite reliability diperoleh nilai terendah pada konstruk social presence sebesar 0,917 dan tertinggi pada konstruk cognitive absorption sebesar 0,941, serta semua nilai composite reliability lebih tinggi dari nilai cronbach's alpha. Berdasarkan hasil pengujian tersebut, dapat dikatakan bahwa pengujian reliabilitas menghasilkan konstrukkonstruk yang reliabel atau telah menunjukkan akurasi, konsistensi dan ketepatan dalam melakukan pengukuran terhadap konsep.

Pengujian structural model dalam PLS dievaluasi dengan menggunakan $\mathrm{R}^{2}$ ( $R$-square) untuk variabel dependen dan nilai koefisien path $(\beta)$ untuk variabel independen yang kemudian dinilai signifikansinya berdasarkan nilai T-statistic setiap path (Hartono \& Abdillah, 2009:133). Hasil pengujian menunjukkan determinasi konstruk independen dalam model yang tinggi terhadap konstruk dependen melalui nilai $R$-square sebesar 0,824 . Hal ini menunjukkan $82,4 \%$ varian student satisfaction dijelaskan oleh variabel cognitive absorption dan social presence.

Mengacu pada Hartono \& Abdillah (2009:63), tingkat signifikansi pengujian hipotesis ditunjukkan dengan nilai koefiesien path atau inner model yang ditunjukkan oleh nilai t-statistik. Hipotesis diterima pada alpha 5\% jika nilai $t$ statistik diatas 1,64 untuk hipotesis satu ekor (one-tailed) dan di atas 2,33 untuk hipotesis satu ekor pada alpha $1 \%$. Berdasarkan nilai t-stastistic pada Tabel 4 , untuk masing-masing path, semua hipotesis yang diuji dalam penelitian ini menunjukkan hasil terdukung.

Hipotesis satu (H1) menyatakan bahwa hubungan antara social presence dengan variabel student satisfaction berhubungan secara positif, dalam pengujian tersebut memiliki hasil positif dengan nilai t-value di atas 2,33 yaitu sebesar 9,142. Begitu juga dengan hipotesis dua $(\mathrm{H} 2)$ yang menyatakan bahwa cognitive absorption berhubungan positif pada student satisfaction mendapatkan hasil positif signifikan dengan nilai t-value sebesar 2,397. Oleh karena itu, kedua hipotesis ini terdukung dengan memiliki tingkat keyakinan $p<0,01$.

Tabel 4. Koefisien Jalur pada Pengujian Model Struktural

\begin{tabular}{lccccc}
\hline \multicolumn{1}{c}{ Path (Hubungan) } & $\begin{array}{c}\text { Original } \\
\text { Sample } \\
(\mathrm{O})\end{array}$ & $\begin{array}{c}\text { Std. } \\
\text { Deviation } \\
(\text { STDEV) }\end{array}$ & $\begin{array}{c}\text { Standard } \\
\text { Error } \\
(\text { STERR })\end{array}$ & $\begin{array}{c}\text { T Statistics } \\
(|\mathrm{O} / \mathrm{STERR}|)\end{array}$ & Keputusan \\
\hline $\begin{array}{l}\text { Cognitive Absorption -> } \\
\text { Student Satisfaction }\end{array}$ & 0,207205 & 0,086434 & 0,086434 & 2,397272 & Terdukung \\
$\begin{array}{l}\text { Social Presence -> Student } \\
\text { Satisfaction }\end{array}$ & 0,718859 & 0,078629 & 0,078629 & 9,142369 & Terdukung \\
\hline
\end{tabular}

Sumber: Data Penelitian, 2019

Hipotesis pertama menyatakan bahwa social presence berhubungan secara positif dengan student satisfaction saat mahasiswa perguruan tinggi vokasi mengikuti kuliah secara daring. Dari hasil pengujian hipotesis diperoleh bukti 
hubungan tersebut terdukung secara signifikan. Hasil yang diperoleh dari penelitian ini sesuai dengan penelitian Richardson \& Swan (2003), Hostetter \& Busch (2006), Horzum (2015), Alsadoon (2018) dan Swan \& Shih (2019) yang menunjukan bahwa student satisfaction dipengaruhi oleh social presence. Sedangkan hasil temuan dari penelitian ini berbeda dengan penelitian Leong (2011) yang tidak diperoleh hasil positif dari hubungan secara langsung kedua variabel tersebut.

Temuan dari pengujian hipotesis 1 mengindikasikan bahwa mahasiswa perguruan tinggi vokasi saat mengikuti kuliah secara daring masih menganggap adanya interaksi antara mahasiswa dan pengajar. Peneliti menduga bahwa kuliah secara daring yang dilakukan selama ini lebih interaktif dan memiliki tingkat partisipasi yang tinggi baik dari mahasiswa dan pengajar, akibatnya dapat memberikan kepuasan sebagaimana yang mereka alami saat kuliah dilaksanakan secara luring (konvensional). Hal ini sesuai dengan yang dikatakan oleh Gunawardena \& Zittle (1997) bahwa mahasiswa akan memiliki perspektif yang lebih baik dan dapat berkontribusi pada komunitas belajar secara daring. Selain itu, temuan ini juga menujukan bahwa mahasiswa yang memiliki pengalaman kuliah secara daring dapat mengembangkan keterampilan belajarnya dan lebih mempu memanfaatkan lingkungan belajar yang dimediasi oleh komputer (Hostetter \& Busch, 2006).

Hipotesis dua yang menyatakan bahwa cognitive absorption mempunyai hubungan positif dengan student satisfaction. Dari pengujian hipotesis diperoleh hasil terdukung secara signifikan dan sesuai dengan penelitian yang dilakukan Leong (2011). Sedangkan hasil penelitian ini berbeda dengan penelitian Rouis (2012) yang tidak ditemukan adanya hubungan antara cognitive absorption dengan kepuasan seseorang menggunakan facebook dan hubungan dengan prestasi akademik. Dengan demikian, hasil penelitian ini memperkuat pernyataan Leong (2011) yang mengatakan bahwa cognitive absorption merupakan salah satu anteseden penting dari terbentuknya student satisfaction.

Terdukungnya hipotesis dua membuktikan bahwa mahasiswa perguruan tinggi vokasi yang terlibat secara mendalam terhadap penggunaan teknologi informasi pada kuliah daring dapat meningkatkan kepuasan dalam proses belajar mengajar tersebut. Temuan ini mengindikasikan bahwa semakin tinggi keadaan cognitive absorption yang dialami mahasiswa seperti mahasiswa memiliki rasa keingin tahuan yang besar terhadap penggunaan teknologi terkait dengan penyelesaian tugas dan mahasiswa memperoleh kesenangan dan kenyamanan, maka hal tersebut dapat semakin meningkatkan kepuasan mahasiswa dalam mengikuti kelas secara daring. Selain itu, cognitive absorption yang mendukung student satisfaction mengandung indikasi bahwa mahasiswa akan lebih dapat mengendalikan waktu penggunaan teknologi informasi dan penggunaannya akan lebih difokuskan untuk tujuan kuliah secara daring.

\section{SIMPULAN}

Dengan menggunakan social cognitive theory, penelitian ini berhasil memberikan bukti bahwa student's satisfaction dapat dipengaruhi oleh social presence dan cognitive absorption dalam konteks penggunaan teknologi informasi untuk kuliah secara daring. Hasil tersebut semakin memperkuat bahwa social presence yang 
tinggi dan mahasiswa mengalami keadaan dari cognitive absorption akan meningkatkan kepuasan mahasiswa seperti saat kuliah secara luring. Walau penelitian ini telah sesuai dengan tujuan yang diinginkan, akan tetapi masih memiliki keterbatasan yang dapat dijadikan pertimbangan dalam penelitian selanjutnya. Keterbatasan pertama adalah penelitian ini menggunakan asumsi lingkungan pembelajaran yang digunakan adalah asynchronous e-learning yaitu pembelajaran yang tidak saling berhubungan di waktu yang sama. Sehingga hasil penelitian tidak dapat digeneralisasi ke lingkungan pembelajaran online yang menggunakan synchronous e-learning atau pembelajaran online yang menggunakan teknologi dua arah seperti aplikasi video conference (Zoom, Google Meet, dll).

Keterbatasan kedua adalah responden yang digunakan adalah mahasiswa perguruan tinggi vokasi. Akibatnya hasil yang diperoleh juga tidak dapat digeneralisasi pada mahasiswa-mahasiswa lainnya terutama yang berasal dari perguruan tinggi S1 karena perbedaan sifat antara sekolah vokasi dengan sekolah jalur akademik. Keterbatasan lainnya adalah penelitian ini hanya menggunakan dua variabel independen dalam menjelaskan pengaruhnya terhadap variabel dependen. Oleh sebab itu diharapkan penelitian selanjutnya dapat menambahkan variabel lain seperti self efficacy, computer anxiety, trust, interest dan lain sebagainya.

\section{REFERENSI}

Agarwal, R., Sambamurthy, V., \& Stair, R. M. (1997). Cognitive Absorption And The Adoption Of New Information Technologies. Academy of Management Proceedings, 293. https://doi.org/10.5465/ambpp.1997.4983719

Agarwal, Ritu, \& Karahanna, E. (2000). Time flies when you're having fun: Cognitive absorption and beliefs about information technology usage. MIS Quarterly: Management Information Systems. https://doi.org/10.2307/3250951

Akcaoglu, M., \& Lee, E. (2016). Increasing social presence in online learning through small group discussions. International Review of Research in Open and Distance Learning, 17(3), 1-17. https:/ / doi.org/10.19173/irrodl.v17i3.2293

Alsadoon, E. (2018). The impact of social presence on learners' satisfaction in mobile learning. Turkish Online Journal of Educational Technology, 17(1), 226233.

Bandura, A. (1977). Self-efficacy: Toward a unifying theory of behavioral change. Psychological Review. https:// doi.org/10.1037/0033-295X.84.2.191

Bandura, A. (1986). Social foundations of thought and action : a social cognitive theory. New Jersey: Prentice-Hall, 1986.

Bolliger, D. U., \& Martindale, T. (2004). Key factors for determining student satisfaction in online courses. International Journal on E-Learning, 3(March), 61-67--.

Chandra, S. (2012). Cognitive Absorption and Trust for Workplace Collaboration in Virtual Worlds: An Information Processing Decision Making Perspective. Journal of the Association for Information Systems, 13(October), 797-835.

Cobb, S. C. (2009). Social presence and online learning: A current view from a research perspective. Journal of Interactive Online Learning, 8(3), 241-254. 
Csikszentmihalyi, M. (2014). Flow and the Foundations of Positive Psychology. In Flow and the Foundations of Positive Psychology. https://doi.org/10.1007/978-94-017-9088-8

Garrison, D. R., Anderson, T., \& Archer, W. (1999). Critical Inquiry in a TextBased Environment: Computer Conferencing in Higher Education. Internet and Higher Education, 2(2-3), 87-105. https://doi.org/10.1016/S10967516(00)00016-6

Garrison, D. R., Anderson, T., \& Archer, W. (2010). The first decade of the community of inquiry framework: A retrospective. Internet and Higher Education, 13(1-2), 5-9. https:// doi.org/10.1016/j.iheduc.2009.10.003

Gunawardena, C. N., \& Zittle, F. J. (1997). Social presence as a predictor of satisfaction within a computer-mediated conferencing environment. International Journal of Phytoremediation, 21(1), 8-26. https:// doi.org/10.1080/08923649709526970

Hair, Jr, J. F. (2015). Essentials of Business Research Methods. In Essentials of Business Research Methods. https:// doi.org/10.4324/9781315704562

Hartono, J. M., \& Abdillah, W. (2009). Konsep \& Aplikasi PLS (Partial Least Square) Untuk Penelitian Empiris. BPFE UGM, Yogyakarta.

Horzum, M. B. (2015). Interaction, structure, social presence, and satisfaction in online learning. Eurasia Journal of Mathematics, Science and Technology Education, 11(3), 505-512. https:// doi.org/10.12973/eurasia.2014.1324a

Hostetter, C., \& Busch, M. (2006). Measuring Up Online: The Relationship between Social Presence and Student Learning Satisfaction. Journal of Scholarship of Teaching and Learning, 6(2), 1-12.

Kosasih, L., \& Iqbal, M. (2013). E-Learning dengan Menggunakan COI Framework. ComTech: Computer, Mathematics and Engineering Applications, 4(2), 856. https://doi.org/10.21512/comtech.v4i2.2523

Leong, P. (2011). Role of social presence and cognitive absorption in online learning environments. Distance Education, 32(1), 5-28. https://doi.org/10.1080/01587919.2011.565495

Leong, P., Ho, C., \& Saromines-Ganne, B. (2002). An empirical investigation of student satisfaction with college courses. E-Learn: World Conference on ELearning in Corporate, Government, Healthcare, and Higher Education, 17921795.

Mirvis, P. H., \& Csikszentmihalyi, M. (1991). Flow: The Psychology of Optimal Experience. The Academy of Management Review. https://doi.org/10.2307/258925

Parameswaran, S., \& Kishore, R. (2017). A social presence model of task performance: A meta-analytic structural equation model. AMCIS 2017 America's Conference on Information Systems: A Tradition of Innovation, 2017Augus, 1-10.

Richardson, J. C., Maeda, Y., Lv, J., \& Caskurlu, S. (2017). Social presence in relation to students' satisfaction and learning in the online environment: A meta-analysis. Computers in Human Behavior, 71, 402-417. https://doi.org/10.1016/j.chb.2017.02.001

Richardson, J. C., \& Swan, K. (2003). Examining social presence in online courses in relation to students' perceived learning and satisfaction. Journal of 
Asynchronous Learning Network, 7(1), 68-88. https://doi.org/10.24059/olj.v7i1.1864

Rouis, S. (2012). Impact of cognitive absorption on facebook on students' achievement. Cyberpsychology, Behavior, and Social Networking, 15(6), 296-303. https://doi.org/10.1089/cyber.2011.0390

Rovai, A. P. (2002). Development of an instrument to measure classroom community. Internet and Higher Education, 5(3), 197-211. https://doi.org/10.1016/S1096-7516(02)00102-1

Sholihin, M., \& Ratmono, D. (2013). Analisis SEM-PLS dengan WrapPLS 3.0 untuk Hubungan Nonlikier dalam Penelitian Sosial dan Bisnis. Andi.

Sorden, S. D., \& Ramírez-Romero, J. L. (2012). Collaborative learning, social presence and student satisfaction in a blended learning environment. Proceedings of the 12th IEEE International Conference on Advanced Learning Technologies, ICALT 2012, 129-133. https:/ / doi.org/10.1109/ICALT.2012.114

Supardi, S. (2014). Pengujian Cognitive Absorption Terhadap KepercayaanKepercayaan Pengguna Untuk Berbagi Informasi Di Lingkungan Virtual Worlds. Jurnal Riset Akuntansi Dan Keuangan, 2(3), 525-549. https://doi.org/10.17509/jrak.v2i3.6602

Supardi, S., \& Asamara, E. N. (2015). Analisis Kepercayaan-Kepercayaan Individu Dalam Menggunakan Teknologi Informasi Dalam Menunjang Proses Belajar Mengajar Di Perguruan Tinggi. Jurnal Manajemen Indonesia, 15(3), 179-194. https:// doi.org/10.25124/jmi.v15i3.715

Swan, K., \& Shih, L. F. (2019). on the Nature and Development of Social Presence in Online Course Discussions. Online Learning, 9(3), 115-136. https://doi.org/10.24059/olj.v9i3.1788

Tallman, F. D. (1994). Satisfaction and Completion in Correspondence Study: The Influence of Instructional and Student-Support Services. The American Journal Of Distance Education, 8(2), 43-57.

Tantri, N. R. (2018). Kehadiran Sosial Dalam Pembelajaran Daring. Jurnal Pendidikan Terbuka Dan Jarak Jauh, 19(2010), 19-30.

$\mathrm{Tu}$, C.-H. (2002). The Measurement of Social Presence in an Online Learning Environment. International Journal on E-Learning, June, 34-45. 